\title{
An extreme case of aortic root pseudoaneurysm after allograft root replacement: A technical challenge
}

\author{
Syed T. Hussain, MD, Eugene H. Blackstone, MD, and Gösta B. Pettersson, MD, PhD
}

Video clip is available online.

A 45-year-old woman presented with an aortic root pseudoaneurysm after having undergone 3 aortic valve operations during the previous 12 months at an outside facility, the last 2 of which were allograft aortic root replacements. The initial surgery was simple aortic valve replacement. She returned after 3 months with prosthetic valve endocarditis, for which she underwent allograft aortic root replacement. Five weeks later, she required another reoperation and allograft root replacement for a root pseudoaneurysm. This time, the left coronary button could not be mobilized but was connected with a vein graft. The reoperation did not resolve her shortness of breath. Repeat imaging showed

From the Department of Cardiothoracic Surgery, Heart and Vascular Institute, Cleveland Clinic, Cleveland, Ohio.

Disclosures: Dr Pettersson reports consulting fees from On-X Life Sciences Inc. All other authors have nothing to disclose with regard to commercial support.

Received for publication March 13, 2014; accepted for publication March 14, 2014; available ahead of print April 19, 2014.

Address for reprints: Gösta B. Pettersson, MD, PhD, Department of Thoracic and Cardiovascular Surgery, Cleveland Clinic, 9500 Euclid Ave/Desk J4-1, Cleveland, OH 44195 (E-mail: petterg@ ccf.org).

J Thorac Cardiovasc Surg 2014;148:3232-3

$0022-5223 / \$ 36.00$

Copyright (C) 2014 by The American Association for Thoracic Surgery

http://dx.doi.org/10.1016/j.jtcvs.2014.03.020

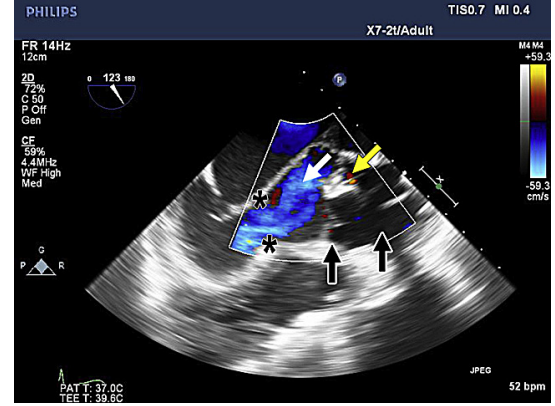

FIGURE 2. Preoperative echocardiogram (in diastole) showing poorly seated allograft (black arrows) with extensive dehiscence, leading to aorto-annular discontinuity and a pseudoaneurysm behind the allograft communicating with the left ventricle (white arrow). Aortic valve regurgitation is trivial. Yellow arrow shows vein graft to left main coronary button; asterisks mark native LVOT.

circumferential dehiscence of the allograft and a huge pseudoaneurysm surrounding the allograft and compressing the left atrium (Figures 1 and 2 and Video 1). The allograft itself had only trivial valve regurgitation. Severely symptomatic, declined for additional surgery, and advised to go to hospice, she presented to our center and underwent her fourth cardiac operation. At reentry, the pseudoaneurysm was surrounding the allograft and expanding posteriorly toward the left above the left atrium, which was compressed and pushed downward. The allograft was circumferentially dehisced
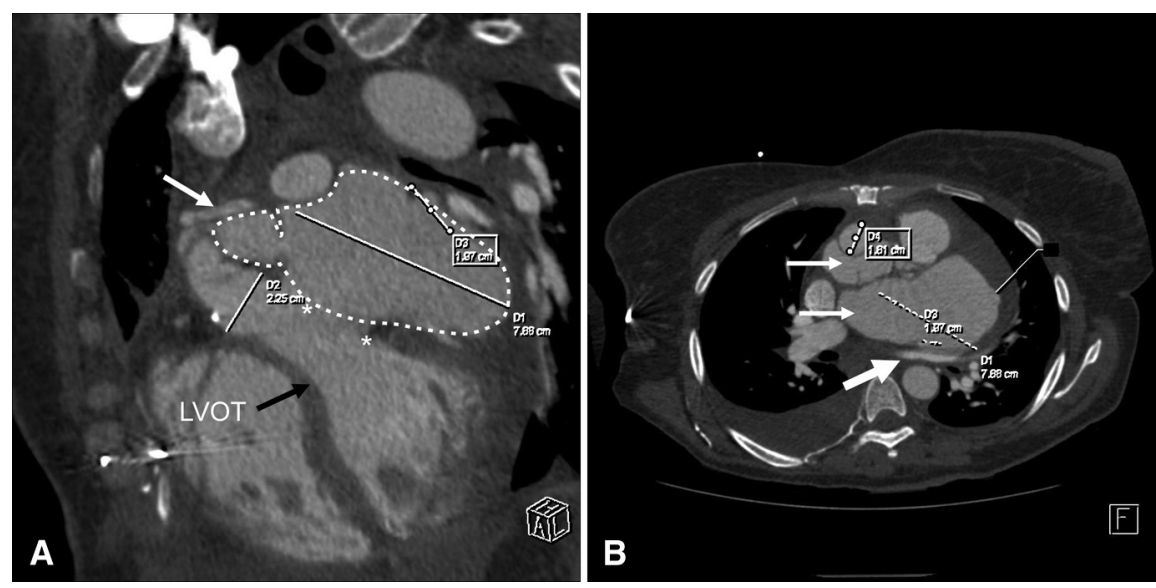

FIGURE 1. Preoperative imaging showing circumferential dehiscence of the allograft and compression of the left atrium by a large pseudoaneurysm. A, Computed tomography image (corono-sagittal view) showing a large contrast-filled cavity $(9 \times 6 \mathrm{~cm})$ above the left atrium, communicating with the LVOT. Another communicating cavity $(4 \times 2 \mathrm{~cm})$ is along the posterior aspect of the proximal ascending aorta. Asterisk shows the separation of the allograft from the LVOT. White arrow shows the vein graft connecting the left main coronary button to the aorta. B, Axial view. Small arrows point to the pseudoaneurysm cavity. The left atrium is severely compressed by the large cavity (large arrow). LVOT, Left ventricular outflow tract. 
and had no contact with the original annulus and left ventricular outflow tract (LVOT). The old allograft and foreign material were removed, and a new allograft was implanted and sutured to the true annulus and LVOT, identified by the 2 trigones and the base of the anterior mitral leaflet, thus excluding the pseudoaneurysm. Her postoperative course was uneventful, and a predischarge echocardiogram demonstrated a competent allograft valve. 